\title{
A Systems-based Approach to Creating Value from Infrastructure Interdependencies
}

\author{
Dr Ges Rosenberg ${ }^{\text {a* }}$ \\ Dr Neil Carhart ${ }^{\mathrm{b}}$
}

\begin{abstract}
Current planning and appraisal processes treat infrastructure as discrete, sector-specific assets, and as a consequence can fail to identify and exploit potentially valuable interdependencies. Similarly, these silo-based approaches are unable to identify potentially hazardous and costly interdependencies in a systematic manner. A major challenge then for providers of modern infrastructure, is to realise the innovative opportunities in interdependencies, and so increase value-for-money, sustainability and resilience. To overcome this, it is necessary to recognise that real-world infrastructure 'systems' are highly interconnected, both with each other and with the socioeconomic and natural systems in which they are located. This paper presents a focused set of the findings from a research partnership between the University of Bristol and University College London, sponsored by HM Treasury in the UK. It proposes an 'open-systems', cross-sectoral approach to create and manage beneficial infrastructure interdependencies, and comprises a framework of principles: 'stewardship', 'shared-governance' and 'interdisciplinarity'; and associated systems-based tools. These have been applied to four case studies relating to the UK's National Infrastructure Programme, three of which are summarized in this paper.
\end{abstract}

\section{Introduction}

Infrastructure fulfils a unique and vital role in society, delivering goods and services both to private citizens, public organisations and private companies, and thereby underpins societal and economic activity. The need for more and better infrastructure is an issue that affects all countries. Current estimates suggest a global need for infrastructure investment of $\$ 57$ trillion by 2030 simply to keep pace GDP growth ${ }^{1}$, and National Infrastructure remains "a major determinant of growth and productivity", and an instrument which governments look to for geographically balancing economic growth and social development.

In the UK, infrastructure development over the last 150 years has been conceptualised and treated for the main part as a series of complicated technical challenges. The focus of the professions (engineers, architects, project managers and economists) has been on commissioning and operating individual infrastructure assets; each of which has been specified and appraised at a given juncture against a current perceived need, for a tightly

\footnotetext{
${ }^{\mathrm{a}}$ Research Fellow, Systems Centre \& Department of Civil Engineering, University of Bristol, Bristol BS8 1UB, United Kingdom ges.rosenberg@bristol.ac.uk

* Corresponding author

${ }^{\mathrm{b}}$ Research Associate, Systems Centre \& Department of Civil Engineering, University of Bristol, Bristol BS8 1TR, United Kingdom http://dx.doi.org/10.14453/isngi2013.proc.39
} 
defined life-expectancy, and then designed, built and operated by an individual industrial sector. As a result, the National Infrastructure Plan $2011^{2}$ characterises the UK's historical approach to the development of national infrastructure as being "fragmented and reactive", noting that "opportunities to maximise infrastructure's potential as a system of networks have not been exploited." There has therefore been a general failure to identify and capture potentially valuable infrastructure interactions, coupled with a lack of systematic identification of potentially hazardous and economically damaging interdependencies. It is also evident that interdependencies, and the attendant benefits and costs, frequently emerge without prior intent to identify or utilise them, even in cases where they may reasonably have been forecasted.

In common with other developed countries, the UK's infrastructure is ageing, frequently beyond its expected design life, added to which socio-economic demands placed upon it are rapidly increasing and changing. This has led to calls for investment to modernise and expand the UK's infrastructure asset base ${ }^{1-5}$. However, ownership of infrastructure and patterns of governance are typically segmented into regulated industrial sectors, adding both institutional and policy barriers to resolve if a more integrated approach is to be implemented.

This research was completed in August 2013 by the University of Bristol's Systems Centre and The Bartlett, University College London ${ }^{6-10}$. Its scope was to investigate an open systems-based approach to creating and managing interdependencies that could sit alongside, and build upon, the existing project appraisal and evaluation process set out in the HM Treasury Green Book ${ }^{12,13}$. The top-level requirements for the Interdependency Planning and Management Framework (IPMF) were identified ${ }^{6}$ as:

1. Provide a systematic process for identifying and handling infrastructure interdependency, including both beneficial interdependencies (benefits and opportunities) and adverse interdependencies (risks and additional costs);

2. Support a process of continual improvement in the handling of infrastructure interdependencies;

3. Support the collective governance of infrastructure;

4. Provide a holistic approach to the measurement and assessment of options;

5. Provide a robust tool to support decision making;

6. Integrate with the existing guidance for project appraisal ${ }^{12,13}$;

7. Facilitate a broad-based approach to stakeholder engagement;

8. Be equally applicable to new and legacy infrastructure;

9. Recognise practical constraints for the purposes of implementation.

This paper presents a focused subset of the findings from the full research programme. It concentrates on the engineering systems toolset used to implement the IPMF for three of the case study applications: Phase 2 of the UK's High Speed 2 Rail project ${ }^{5}$; the Lower Thames Crossing ${ }^{14}$; and Engineering the Future's National Infrastructure Timelines project ${ }^{15}$. Although the framework has been used to identify, represent and analyse both positive (beneficial) and negative (adverse) interdependencies, this particular paper focuses solely on how the approach and tools can be used to innovate and create value from beneficial infrastructure interdependencies. The framework has been developed as a generic set of principles and processes, and hence a wide range of planning and systems engineering toolsets could be deployed to implement the approach. Typically these might include use case analysis, systems dynamics modelling, influence diagramming, scenario planning, stakeholder analysis, multi-criteria assessment (MCA), uncertainty management techniques, 
impact assessment and sustainability appraisal frameworks ${ }^{6,16-19}$. For the case studies presented, a matrix mapping approach (after Lano ${ }^{20}$ ) was used to implement the framework.

\section{Development of the Interdependency Planning and Management Framework}

At the core of the resulting framework is a set of systems thinking principles, processes and tools which aim to drive infrastructure proposers and delivery teams to look for a) beneficial interdependencies with other infrastructure and policies (synergies), and b) problematic dependencies (systemic vulnerabilities or conflicts) to be managed. By exploring, and potentially expanding the boundary, planners and engineers are free to identify the principal 'soft' and 'hard' systems with the potential to interact with the core infrastructure system(s) being developed. The approach requires policy makers, economists, planners and engineers to adopt four key principles:

1. That infrastructure development requires a holistic, open systems view of infrastructure, and hence recognise and adopt a 'system of systems' perspective.

2. That all 'hard' infrastructure systems are developed within a framework of 'soft' systems comprising policies, regulations, processes and practices, coupled with the institutions, organisations and people that define and implement them.

3. To question and explore the accepted and/or perceived system boundary for an infrastructure development in order to engage with a wider range of stakeholders and create the potential for innovative project scoping and design options.

4. To develop a strategic governance or 'stewardship' approach for infrastructure. This requires a shift away from an individual asset management perspective, and instead requires a wide range of institutions and enterprises to collaborate in developing a coherent framework of policies, plans, processes and institutions to guide future infrastructure investment and planning.

The proposed framework is implemented through three groups of activities: 1) Problem Structuring; 2) Measurement and Appraisal; and 3) Creating Stakeholder Understanding. These activities are undertaken iteratively and in some cases concurrently, and are informed by an evolving and maturing knowledge base in interdependency planning and management ${ }^{21}$.

In the context of the framework (see Figure 1), Problem Structuring is defined by eight sub-activities:

1) Explore the system boundary and policy context ${ }^{22,23}$. This preliminary activity formally embodies the three principles above into the framework process. It provides the opportunity for creative thinking during infrastructure planning, appraisal and design, and promotes participation from a broad group of relevant stakeholders.

2) Establish and frame the core development needs. This is necessary to ensure that criteria of success for the core development goal can be established, and therefore that the cumulative effects of beneficial and adverse interdependencies can be appropriately framed and assessed in the appraisal process.

3) Explore the boundary and context to the infrastructure needs. It is necessary creatively and systematically to search and reveal the relationships between the defined need for the core intervention and other socio-economic and environmental needs and policy goals which comprise the 'context'. 
4) Identify the architecture of the infrastructure network. The systems architecture provides a high-level, conceptual model that depicts the structure of a given system, and the interactions it has with other hard and soft systems. This captures and represents the planned development and its relationships with other infrastructure. It allows for the general nature of the infrastructure development to be communicated with stakeholders, and provides a platform for identifying interdependencies.

5) Identify interactions with additional socio-economic and environmental needs. Engagement with a broad spectrum of infrastructure stakeholders is important to identify both core and additional higher-level needs which could be met by the core infrastructure development.

6) Identify opportunities to develop beneficial interdependencies ${ }^{24}$. This may occur when defining the infrastructure need, when setting the objectives and appraising a project, and during implementation and post-project evaluation and upgrade.

7) Identify risks from adverse interdependencies. The risks from adverse interdependencies $^{25}$ should be identified throughout the planning, design, implementation and operation of the infrastructure, and it is particularly beneficial to apply them early on before project goals have been substantially set.

8) Define objectives for interdependency planning and management. Planning of options can now be guided by decisions over which beneficial interdependencies should be incorporated into the scope of core infrastructure project, as supported by the engineering analyses and economic appraisal.

The Measurement and Appraisal leg of the framework comprises three activities:

1) Establish criteria to validate interdependencies. The value of the beneficial interdependencies should be assessed and validated, for example using a MultiCriteria Analysis (MCA) ${ }^{16}$. A range of holistic appraisal tools have been developed, generally based around PESTLE ${ }^{\mathrm{c}}$ and other sustainability checklist approaches, and these provide a useful means of identifying appropriate decision criteria. Similarly criteria for assessing the adverse impacts from negative interdependencies will be need to be established at this stage in the process, for example defining the levels of probability and impact commonly used in probability-impact approaches to risk assessment $^{26}$.

2) Gather evidence and appraise interdependencies. Evidence to support the appraisal of interdependencies is compiled throughout the stages of: 1) exploring the systems boundary and context; 2) the creation of stakeholder understanding; and 3) during the identification of positive and negative interdependencies. The approach to appraising interdependencies should be consistent with the overall appraisal process for the main project.

3) Review business case against maturity of interdependency management. Criteria setting out levels of maturity in interdependency planning and management would need to be established in areas such as willingness to collaborate; openness of contractual and commercial management; capability to manage complex crosssectoral projects; risk appetite of investors; and engineering design and economic appraisal toolsets. The business case for any proposed interdependency should be reviewed against a framework of organisational maturity criteria to ensure there is sufficient capability and willingness in partnering organisations and industrial sectors to deliver planned interdependencies successfully. 
The successful application of the two stages above relies upon the engagement of a wide selection of stakeholders, and processes to Create Stakeholder Understanding as follows:

1) Identify cross sector stakeholders for potential collaboration. Effective and early engagement with a diverse but relevant set of stakeholders $^{27}$ is critical if a more comprehensive and robust set of interdependencies is to be identified, appraised and adopted. Early engagement will reduce the risk of major design changes being required subsequently, discourages the premature adoption of solutions dominated by one specific technology or sector, and help to avoid the premature discarding of options.

2) Develop interdependency planning and management practice. The IPMF recognises that there is a need to embed a context-dependent learning process that can inform the development of strategic policy, governance/stewardship and valuation of infrastructure and associated interdependencies on a continual basis.
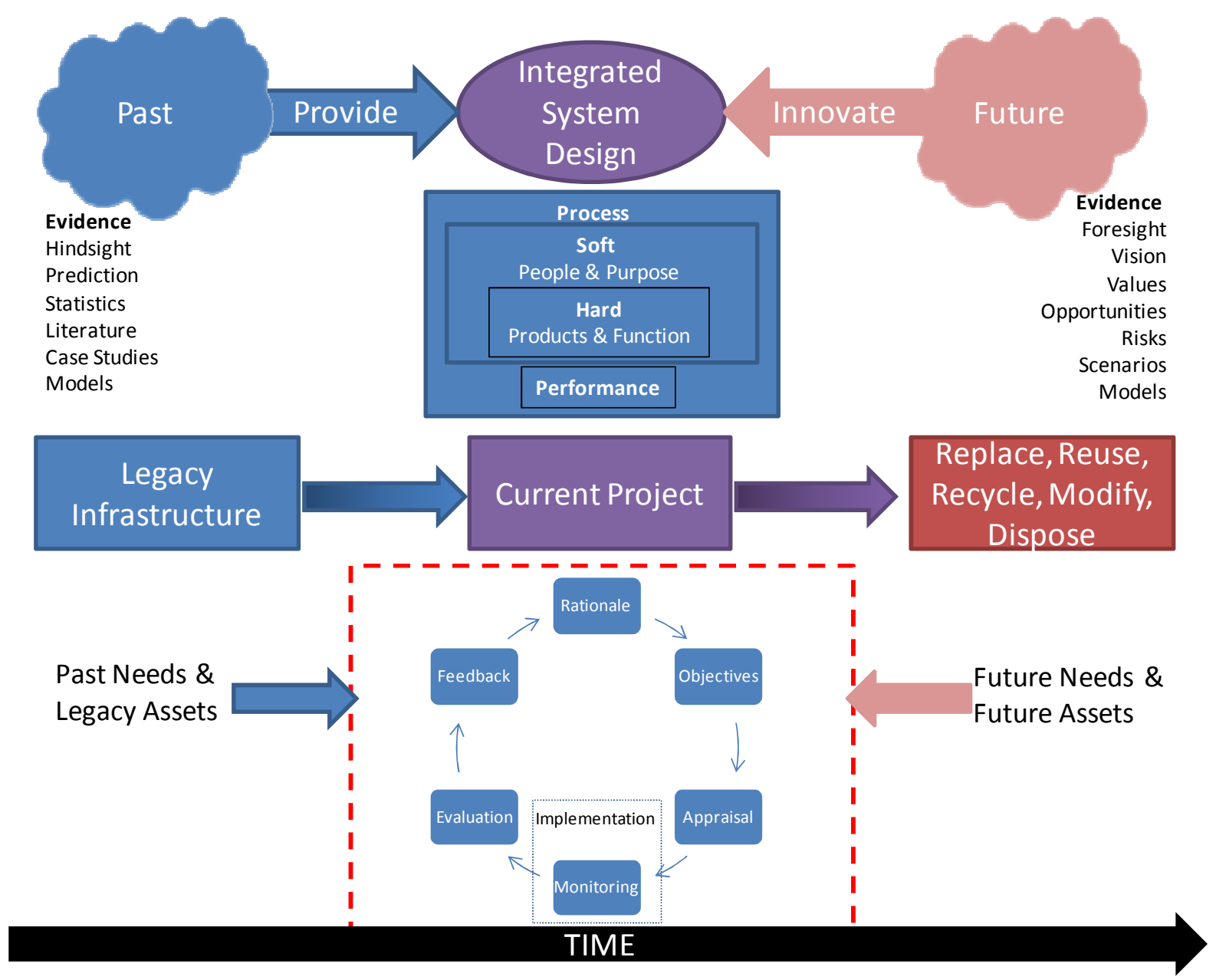

Figure 1. Schematic of interdependency Planning and Management Framework. 


\section{Case Study Applications}

\section{A. Phase 2 of the UK's High Speed 2 Rail Project}

Background: The lack of capacity on the UK's railway network routes presents a major transport and economic development issue for the UK Government. The High Speed 2 (HS2) rail project ${ }^{5}$ is being proposed to increase public transport capacity linking major urban areas in the North of England, the Midlands and London. The economic case for a high speed rail solution is built predominantly upon travel cost savings. The political case rests in part on an expectation that new infrastructure will also promote economic growth in the North of England, thereby contributing to a geographic 'rebalancing' of the UK's economy. The case study investigated beneficial engineering interdependencies along the planned HS2 routes from Birmingham onto Leeds and Manchester, with the aim of supporting the UK Department for Transport in scoping the route consultation.

Method: A workshop was held to engage participants from four different infrastructure sectors: Energy, ICT, Water and Transport. This provided a means to engage with relevant stakeholders and explore the context and boundaries to the HS2 Phase 2 project in an opensystems manner, and hence link HS2 assets and operations to the UK's policy context across multiple sectors. A matrix-based approach was used to structure the exploration of interdependency, and to identify innovative options to enhance the core rail project. Following this, participants were asked to compile an assessment of the evidence, both in support of and against the interdependencies, using a PESTLE-based tool. Necessarily this assessment of opportunities was cross-sectoral, broad ranging in scope, and qualitative, although numerical data was gathered where this existed.

Results: Twenty four potential interdependencies between the HS2 Phase 2 project and other infrastructure sectors were identified. (An example of the output from the workshop is presented in Figure 2 for the Water Sector-HS2 interdependencies.) Of the 24 interdependencies, five, were identified as being of high significance:

- Using High Speed 2 Phase Two corridor to provide additional electricity distribution capacity into Sheffield and Manchester. Combining HS2 Phase 2 with projects to enhance electricity distribution would consolidate and reduce visual blight and disruption during construction, though there would be issues over ownership, legislation and regulation. Economically, a single integrated project may be favourable as the total cost would be less than for two separate projects (e.g. for planning, consultation and tunnelling), and it would support and align increased economic activity in these regions. In social terms, city regions are expected to grow, with the expectation that HS2 would also contribute to stimulation of population growth. Additional and diverse routing of the electricity network should also improve its resilience.

- Using High Speed 2 Phase Two corridor to provide a bulk water transfer route between the north and south. Schemes for the bulk transfer of water from NorthWest England, where there is abundant rainfall, to South East England have been proposed in the past. Most recently United Utilities proposed a £2.6 billion NorthSouth water pipe using the route of $\mathrm{HS}^{28}$. However, cost estimates suggest this would be an expensive solution compared to alternatives, added to which 25 -year water resource plans delivered under the UK water industry regulations suggest such solutions should not be required during this timeframe. Although bulk water transfer would potentially enhance resilience to drought, it also has the disadvantage of 
increasing energy consumption ${ }^{29,30}$, and there is the potential of such a co-located pipe bursting and forcing rail track closures. This interdependency although significant was therefore discounted at the workshop.

- Using High Speed 2 Phase Two corridor to provide the capability for inter-regional water transfer. From an economic perspective the pricing principles for trading across water regions are in place and such an approach could provide a cheaper alternative to other water resource development options such as local interconnecting pipelines. For example, some water supply regions tend to be weakest at their extremities, so transporting water from neighbouring areas with an excess of water resources would be rational from a whole sector standpoint. It would also add to the resilience of the total UK water supply network and from an environmental perspective it could help regulators balance abstraction licensing against supply needs. The concept of water transfer between water companies and water supply zones has been explored by Water UK, and the United Utilities $55 \mathrm{~km}$, $£ 120 \mathrm{~m}$ bi-directional pipeline between Manchester and Liverpool (West-East Link Main) is an example of the recent development of this type of infrastructure ${ }^{31}$.

- Using High Speed 2 Phase Two corridor (and associated construction) to provide the capability for additional flood protection (see Figure 2). Such an approach could be of significant socio-economic value in terms of enhanced flood protection for householders and businesses, and of interest to insurers and government. Politically it would also be attractive if the HS2 Phase 2 project brought further benefits beyond the public transport sector. It was noted that a report by Engineering the Future ${ }^{32}$ supports the potential for the use of railway embankments as flood defences, whereas a joint report by DEFRA and the EA $^{33}$ indicates that existing rail embankment designs are not 'fit-for-purpose' as flood defences though they may provide a partial barrier. While the proposal is technologically achievable, it would come at additional costs, and furthermore the dynamic effects in flood plains are uncertain, adding to uncertainties due to climate and land use changes. However, the workshop concluded that such a scheme could be feasible and would create an overall positive benefit for the UK.

- Using High Speed 2 Phase Two corridor to provide additional capacity for the distribution of ICT infrastructure (e.g. fibre optic cables)._The principal value would accrue by helping achieve UK national connectivity targets with less disruption than installing new separate ICT infrastructure. This option could offer diversity to the UK's ICT network, and may in the short term simply require a level of provisioning for future installation of ICT hardware. Economically this opportunity could provide an efficient route, with low latency making the relocation of data centres outside London more attractive, and this in turn could create new job opportunities outside of the London area. It could also be used to boost rural economies along the HS2 route. A countervailing view was that the HS2 project may be too late to assist in achieving UK connectivity goals, and by the time the project is operational, the need for additional fibre cables may have been superseded by alternative wireless technologies such as 4G. Support in the literature for this interdependency includes reports by Frontier Economics ${ }^{24}$ and $\mathrm{OECD}^{3}$. 


\begin{tabular}{|c|c|c|c|c|c|}
\hline & 1 & 2 & 3 & 4 & 5 \\
\hline A & $\begin{array}{l}\text { Climate } \\
\text { Change }\end{array}$ & - & $\begin{array}{l}\text { May result in } \\
\text { increased rainfall in } \\
\text { North \& decreased } \\
\text { rainfall in South }\end{array}$ & $\begin{array}{c}\text { May result in } \\
\text { increased rainfall in } \\
\text { North \& decreased } \\
\text { rainfall in South }\end{array}$ & - \\
\hline B & - & $\begin{array}{c}\text { Flood } \\
\text { Protection }\end{array}$ & - & - & $\begin{array}{c}\text { Affects resilience of } \\
\text { the railway }\end{array}$ \\
\hline C & - & - & $\begin{array}{l}\text { Intra-Region } \\
\text { Transfer }\end{array}$ & - & - \\
\hline D & - & - & - & Bulk Transfer & - \\
\hline $\mathrm{E}$ & - & $\begin{array}{c}\text { HS2 } \\
\text { embankments } \\
\text { provide } \\
\text { opportunity for } \\
\text { flood detention } \\
\text { storage }\end{array}$ & $\begin{array}{c}\text { Provide route for } \\
\text { pipeline to strengthen } \\
\text { interconnections } \\
\text { between water } \\
\text { supply zones }\end{array}$ & $\begin{array}{l}\text { Provides route for } \\
\text { North-South bulk } \\
\text { water transfer } \\
\text { pipeline }\end{array}$ & $\begin{array}{c}\text { HS2 Phase } 2 \\
\text { Rail Line \& Route }\end{array}$ \\
\hline
\end{tabular}

Figure 2. HS2-Water Sector Opportunities to Engineer Interdependency

The interdependencies identified during this case study cross the traditional boundaries of infrastructure sectors, and developing them effectively requires the HS2 project to be viewed as more than the provision of additional rail capacity and reduced journey times, important as these aims are. The outcome from this research contributed to the HS2 Phase 2 Route Consultation $^{5}$ which states in paragraph 11.06:

"We have been looking into whether provisions could be made along Phase Two of the HS2 network for other utilities such as water, electricity or integration with flood management schemes. This could further enhance the benefits brought to the country by HS2 while creating jobs and driving growth."

\section{B. Lower Thames Crossing}

Background: The existing Dartford to Thurrock Thames River crossing is an important part of the UK's national, regional and local road networks, but studies have found that the existing crossing acts as a 'bottleneck' during peak times. Added to this, a large number of urban regeneration projects are proposed for the Thames gateway area, and traffic forecasts predict the need for increased transport capacity across the Thames. As a result the National Infrastructure Plan $2012^{2}$ has identified the Lower Thames Crossing (LTC) as one of 40 projects of national significance.

There is an obvious interdependency between the need for a new crossing and planned urban regeneration: the effectiveness of the existing and new crossings can impact on the delivery and success of these regeneration activities, whilst the regeneration itself places further demands on the existing and planned crossings. Nevertheless, the LTC project ${ }^{14,36}$ is primarily motivated by a projected traffic capacity problem and is expected to proceed largely independently from decisions involving the planned regeneration projects. It is also 
clear from documentation that the regeneration projects will proceed regardless of decisions surrounding the LTC project. Desirable and undesirable interdependencies may therefore emerge, and the IPMF was applied to help understand these and identify the potential to plan and design for beneficial interdependencies.

Method: The framework and tools were applied in a desktop study of reports and literature for the LTC and other the infrastructure and regeneration projects proposed within the region. A matrix map was used to capture systematically the cross-sector interdependencies which were characterised and evaluated in terms of PESTLE factors. The resulting model was used to explore the system boundary, understand the core needs and policies driving the LTC project, and to identify a broad set of stakeholders with interest in the potential interventions and impacts. The output of this desk study was presented to these stakeholders who were then given the opportunity to add interdependencies, re-characterise and re-evaluate them, and provide additional. The stakeholder engagement provided a richer understanding of the architecture of the systems involved, and an identification of conflicting or compatible needs and policies.

Results: Forty-eight high-level interdependencies were identified from the desk study. Some of these are only applicable if the crossing is placed in a particular location and takes a particular form (e.g. bridge or tunnel). Some are necessary for the crossing to function; others are potential interdependencies which could enhance the LTC or external projects; and some present risks for the LTC project. In line with current assessment criteria, the wider regional economic impacts of the crossing have been broadly considered, but there is little evidence that this has extended to a consideration of the project as a proactive 'agent of change ${ }^{19}$. The additional, potentially valuable interdependency opportunities include:

- Using Lower Thames Crossing structure to provide the capability for additional electricity generation. The specific nature of this would depend on the form of the crossing, but suggestions include using traffic vibrations, excess heat, photovoltaic cells or tidal mechanisms to generate electricity through the crossing structure, e.g. using the crossing structure to create a tidal lagoon for electricity generation14. As Figure 3 shows, some dependencies are necessary for the LTC to function (e.g. power for lighting), while others are potential opportunities (e.g. to generate electricity), or hazards and obstacles (e.g. large pylons).

- Using Lower Thames Crossing to provide a capability for cross-river distribution of electricity, telecommunications, water, and waste infrastructure elements. Such schemes would be relatively straightforward in engineering design terms, and could add value from political, environmental and social perspectives, as well as allowing for sharing of construction costs. Downsides include more complications in project delivery, and in shared asset ownership or access rights for maintenance and operation.

- Using Lower Thames Crossing structure to provide a capability for additional flood defences. This interdependency would require alignment of a flood protection barrier planned under the Thames Estuary 210034 project with the LTC at Gravesham to Thurrock. The benefits and risks of delivering both large-scale infrastructure projects as an interdependent structure would require additional investigation.

- Using recycled materials in the construction of the Lower Thames Crossing. This would create a construction phase interdependency between the LTC and other local 
and regional projects, i.e. other construction projects or the waste/recycling sector could provide materials for the road base or surface, and reciprocally, the LTC could make use of what would otherwise be wasted by-products. This might be in the form of recycled aggregate, building materials or even car tyres (as implemented on the A90 between Perth and Dundee35).

- Sharing resources between the construction of the Lower Thames Crossing and other local regeneration and National Infrastructure projects. This approach has the potential to deliver cost savings in the form of shared equipment, coordinated resource and supply chain management, and joint training schemes.

Overall, this case study showed that an 'open systems' perspective allows for greater consideration of the ways in which interdependencies could be 'engineered' into an infrastructure and deliver regeneration in ways that extend beyond those typically associated with mega transport projects.

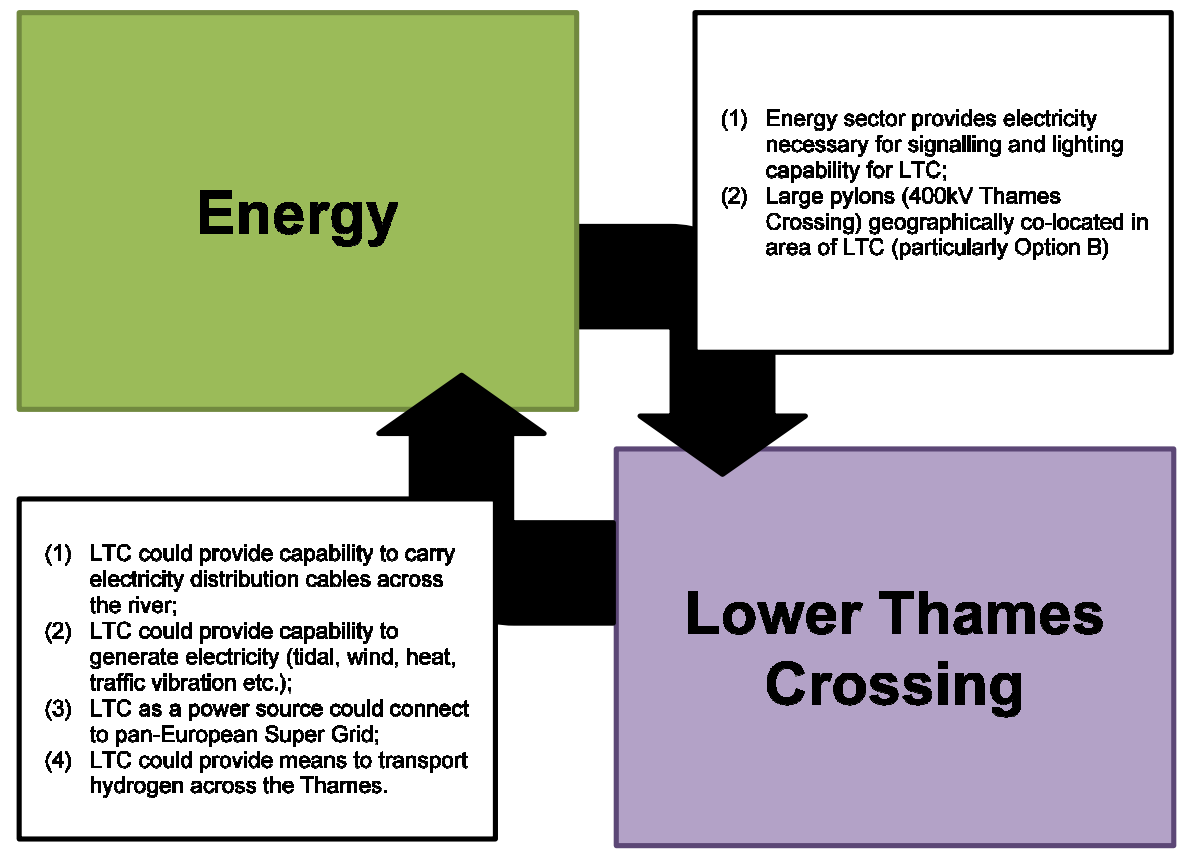

Figure 3. Energy Infrastructure \& LTC Interdependencies.

\section{Engineering the Future's Infrastructure Timelines Project}

Background: Engineering the Future ran a project to capture timelines for the next 40 years of UK infrastructure planning across five sectors: Energy, ICT, Transportation, Waste, and Water $^{37}$. The IPMF was applied to identify areas where a lack of planning and appreciation of interdependency might be problematic, and where beneficial interdependencies might otherwise be overlooked.

Method: A workshop ${ }^{10,37}$ provided the means to bring together a diverse group of stakeholders from across the five timeline sectors, each with an interest in a relevant policy area or timeline project. It included representation from industry and academia, as well as those involved with governance. Initially interdependencies were identified within each sector between policies and the timeline projects. Following this, participants were challenged to identify and analyze interdependencies arising out of interactions present across all five timeline sectors, policies and projects. The inclusion of policy in this 
assessment brought a wider context to the interdependency mapping, including socioeconomic and environmental needs. The information used to develop the model came from project documentation, policies and plans, together with the domain knowledge of the workshop participants.

Results: Ninety-one interdependencies were identified ${ }^{10}$ when analysing the relationships within each of the five sectors, i.e. intra-sector interdependencies. These comprise:

- Twenty-seven relationships within the energy sector spanning five projects and policies (Smart Grids, Exiting Building Use, Nuclear, Heating and Community Energy and Gas). The Smart Grid project (and associated policies) was identified as being a significant potential opportunity when integrated with the other elements, providing the means to optimise sector performance. It was also noted that achieving the potential benefits of Smart Grids was dependent on projects within the ICT sector.

- Fifteen interdependencies were identified within the transport sector projects and policies, four involving ownership and funding of the highways network. For example collaboration would be advantageous between the stakeholders seeking highways funding and those involved with managing airport capacity, HS2 rail and the London Gateway. Discussion also covered the interaction between national and local road usage, i.e. although night time use of motorways presents an underutilised asset, local policies restrict the nocturnal movement of freight. Collaboration to integrate and align policy in these areas could leverage underutilised assets and enhance a project's business case. It was also noted that the potential benefits from HS2 are not limited to the boundary of a rail project, but that wider benefits come from the potential transfer of traffic from the highways, hence contributing to the UK's emissions reduction strategy.

- Twenty five interdependencies were identified in the ICT and waste sectors combined. The emergence of 'Internet of Things tagging' (through RFID tags or QR codes) was revealed as a strongly interdependent technology with the potential for widespread benefits especially when integrated with other projects, e.g. recycling rare materials, the identification and tracking of suitable feedstock from waste for anaerobic digestion, and the location and classification of spatially distributed assets, including satellites. The effectiveness of this emerging technology is itself dependent on a resilient and capable broadband connectivity with nationwide coverage.

- Twenty four interdependencies were in the area of water infrastructure, including abstraction consenting and the natural environment, bulk water transfer, flood protection, infrastructure resilience, rainfall run-off and water treatment. For example, flood waters could be transferred and used for bulk supply, to recharge aquifers, with long-term implications for abstraction and the natural environment.

A further eighty-four interdependencies were identified when assessing interactions between the five sectors, i.e. inter-sector interdependencies. Figure 4 illustrates the number of dependencies or interdependencies that were identified within and between the sectors. It shows the high density of interaction between the ICT and Transport sectors, and between the Energy sector and all other sectors. The following points summarise the main findings: 
- Strong relationships between ICT and transport sector projects, with transport relying heavily on ICT to operate efficiently and effectively. Specific interdependencies identified include opportunities to reduce the need for physical travel by enhancing ICT capability (e.g. ubiquitous videoconferencing); the colocation of assets such as laying cabling alongside transport corridors; and information management and control services (e.g. route planning, transport management systems, congestion charging and enhanced train management to increase network capacity).

- Strong coupling between the energy sector and each of the other four sectors, with energy obviously playing a role in underpinning operations in the other sectors. Other specific interdependencies identified in this area include: Smart Metering impacting on energy usage; energy distribution and transport assets sharing physical space; opportunities to harness waste vehicle heat from tunnels; the energy sector providing fuel and lubricants for transport; transport of solid, liquid and gas fuels; and potential interactions between shale gas production and water abstraction and wastewater treatment.

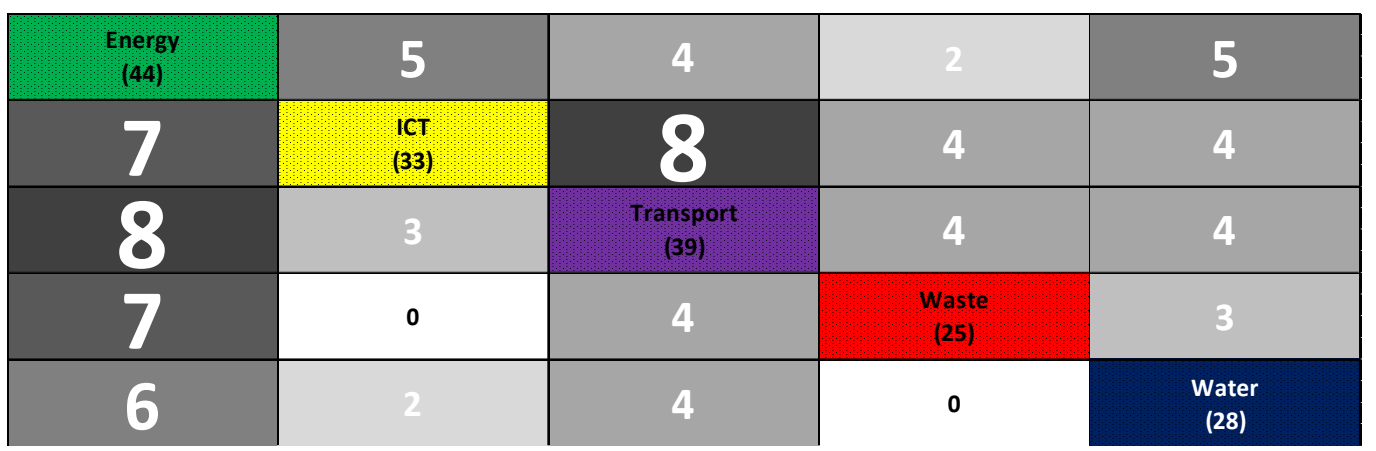

Figure 4. Density of Cross-Sectoral interdependencies for Timelines Project.

\section{Conclusion}

The importance of interdependency management is beginning to be widely recognised by government, businesses and academics. This is evidenced in recent reports commissioned by the UK Government on nationally significant projects such as the recent HS2 Phase 2 consultation $^{5}$ and the Frontier Economics report ${ }^{25}$ on systemic risks and opportunities.

If infrastructure providers are to generate opportunities and benefit from the interconnectedness of infrastructure networks and the environment in which they are embedded, then new planning and engineering approaches will be needed to analyse and create beneficial interdependent relationships. Integration of transport infrastructure is one long-standing example, illustrating both the challenge of complexity and the potential value from harnessing interdependency. Other examples of potentially beneficial infrastructure interdependencies have been identified in this paper.

Due to the highly interactive way in which people use infrastructure, it is important to be able to identify and model not just discrete infrastructure components in isolation, but also the interconnections, and recognizing this comprises the core of interdependency 
identification and modelling. The evidence from literature such as the OMEGA Centre research into mega-transport projects ${ }^{17-19}$, clearly indicates the need for engagement and involvement with a wide range of stakeholders early on in the project lifecycle, before the project is committed in terms of definition and scope. The research is also strongly supportive of open systems approaches, with a central focus on the importance of understanding the context in which proposed infrastructure is to be developed, and the transformative, coevolutionary nature of such large scale developments.

Although design of positive interdependencies cannot be achieved by a simple mechanistic process, a range of existing systems engineering or systems architecting tools exist which have a long-standing applications in the design of complicated aerospace, marine, ICT and rail industrial sectors. The potential usefulness of such tools has been illustrated in this paper by the application of a matrix-based mapping tool to planned UK National Infrastructure. Implementing a structured and systematic search for interdependencies in this way has the potential both to challenge and complement existing planning and engineering practices in the design of infrastructure provided the transfer to this new application area is tested and reflexively developed.

The description of the IPMF process developed under contract to HM Treasury has been presented, together with an implementation of this based around a PESTLE and matrix mapping toolset. The elements of the framework have been demonstrated in three major case studies and found to provide an acceptable and intuitive approach by the stakeholders participating in the associated workshops. It should be noted though that a wide range of other tools exist that could be used to implement the framework. The key achievement for the interdependency framework and toolset developed under this project has been to develop an approach that facilitates innovation, but which is also intuitive and readily applied across sectors and academic disciplines.

The further conclusion reached from this research was the importance of bringing together stakeholder views from a broader community than would normally be consulted, if a more creative assessment of interdependencies is to be effected. In particular, this is based on the evidence from the contrast between the desktop based reviews of interdependency and those of the case studies based on workshop interactions. The pitfall of a desktop-based review of interdependency is to pursue an insular planning approach that will do no more than: a) catalogue well-known interdependencies as established on similar previous projects and simply apply a scalar to these patterns of development; and b) to do this with a disciplinary bias towards the negative, risk aspects of interdependency.

\section{References}

${ }^{1}$ McKinsey Global Institute, Infrastructure productivity: How to save \$1 trillion a year, 2013. ${ }^{2}$ HM Treasury, "Infrastructure UK," National Infrastructure Plan 2011, 2011.

${ }^{3}$ OECD, Infrastructure to 2030: Telecom, Land Transport, Water and Electricity, 2006.

${ }^{4}$ Council for Science and Technology, A National Infrastructure for the 21st Century, 2009.

${ }^{5} \mathrm{HS} 2$ Ltd., High Speed Rail: Investing in Britain's Future - Consultation on the route from the West Midlands to Manchester, Leeds and Beyond, 2013.

${ }^{6}$ Systems Centre, University of Bristol and The Bartlett, University College London, The Development of a Preliminary Framework for the Identification and Appraisal of 
Infrastructure Interdependencies with Application to UK National Infrastructure. Technical Report, Issue 1, 14 December, 2012.

${ }^{7}$ Systems Centre, University of Bristol and The Bartlett, University College London, Exploring the Potential for Installing Dark Fibre on the HS2 Pathway. Technical Report, Issue 1, December, 2014.

${ }^{8}$ Systems Centre, University of Bristol, Identification of High-level Infrastructure Interdependencies for the Lower Thames Crossing: Case Study Report for Infrastructure UK, Draft Report, July, 2013.

${ }^{9}$ Systems Centre, Univ. of Bristol, Identification of High-level Infrastructure Interdependencies for HS2 Phase 2 Proposed Route: Workshop Data Report for Infrastructure UK, Department for Transport and HS2 Ltd, Draft Report, April, 2013.

${ }^{10}$ Systems Centre, University of Bristol, Workshop Application of a Matrix Based Approach to the Identification of Infrastructure Interdependencies - Workshop Report for Engineering the Future, 2013.

${ }^{12} \mathrm{HM}$ Treasury, The Green Book - Appraisal and Evaluation in Central Government, 2003.

${ }^{13}$ HM Treasury, Valuing Infrastructure Spend: Supplementary Guidance to the Green Book, 2011.

${ }^{14}$ Parsons Brinkerhoff, Dartford River Crossing Study, 2009.

${ }^{15}$ Engineering the Future, UK Infrastructure Timelines, 2011.

${ }^{16}$ Department for Communities and Local Government, Multi-criteria analysis: a manual for good practice, 2009.

${ }^{17}$ Omega Centre University College London, Dimitriou, H.T., Harman, R., Ward, E.J., Incorporating Principles of Sustainable Development within the Design and Delivery of Major Projects: An international study with particular reference to mega urban transport projects, Final Report. London: OMEGA Centre, University College London, 2010.

${ }^{18}$ Omega Centre, University College London, Investigation into the Development of a Framework for the Identification and Appraisal of Infrastructure Interdependencies with Application to Critical UK Infrastructure, London, 2012.

${ }^{19}$ Omega Centre, University College London, Mega Projects and Mega Risks: Lessons for Decision-makers through a Comparative Analysis of Selected Large-scale Transport Infrastructure Projects in Europe, USA and Asia Pacific, Final report of a five year international research programme, London, 2011.

${ }^{20}$ Lano, R.J., A technique for software and systems design, Elsevier North-Holland Pub. Co., 1979, pp. 119.

${ }^{21}$ Australian Government - Australian Public Service Commission, Tackling Wicked Problems - A Public Policy Perspective, 2007.

${ }^{22}$ Von Bertalanffy, L., General System Theory: Foundations, Development, Applications, George Braziller, 1968.

${ }^{23}$ Beckford, J., Systems Engineering: Necessary but not Sufficient for 21st Century Infrastructure, 2013.

${ }^{24}$ Frontier Economics, Systemic Risks and Opportunities in UK Infrastructure - A Report Prepared for HM Treasury \& Infrastructure UK, 2012.

${ }^{25}$ HM Government Cabinet Office, Strategic Framework and Policy Statement on Improving the Resilience of Critical Infrastructure to Disruption from Natural Hazards, 2010.

${ }^{26}$ Government Office for Science, Blackett Review of High Impact Low Probability Risks, 2011.

${ }^{27}$ Zachman, J.A., "A framework for information systems architecture," IBM Systems Journal, IBM, Vol. 26, No. 3, 1987, pp. 176-292. 
${ }^{28}$ Drought pipeline proposal for HS2 route | Magazine News | New Civil Engineer [Internet], URL: http://www.nce.co.uk/news/water/drought-pipeline-proposal-for-hs2route/8627114.article

${ }^{29}$ Water UK says High Speed 2 water pipeline could be "insurance policy" [Internet], URL: http://www.waterbriefing.org/index.php/home/water-issues/item/5418-water-uk-sayshigh-speed-2-water-pipeline-could-be-\%E2\%80\%9Cinsurance-policy\%E2\%80\%9D

${ }^{30}$ House of Commons, Uncorrected Transcript of Oral Evidence - HC 1852-iii: Oral Evidence taken before the Environent, Food and Rural Affairs Committee "The Water White Paper" [Internet], 2012.

${ }^{31}$ Case Study: West East Link pipeline [Internet], 2013.

${ }^{32}$ Engineering the Future, Infrastructure, Engineering \& Climate Change Adaptation Ensuring Services in an Uncertain Future, 2011.

${ }^{33}$ Morri, M., Dyer, M., and Smith, P., Management of flood embankments: A good practice review, 2007.

${ }^{34}$ Environment Agency, Thames 2100 Plan: Managing flood risk through London and the Thames estuary, 2012.

${ }^{35}$ Innovative approach to resurfacing road - South Lanarkshire Council [Internet], 2013.

${ }^{36}$ Aecom, Review of Lower Thames Crossing Options: Final Review Report, 2013.

${ }^{37}$ Engineering the Future, Infrastructure Interdependencies Timelines, 2013. 